Fixed Point Theory, 20(2019), No. 1, 365-388

DOI: $10.24193 /$ fpt-ro.2019.1.24

http://www.math.ubbcluj.ro/ nodeacj/sfptcj.html

\title{
ON SOLVING THE VARIATIONAL INEQUALITY AND FIXED POINT PROBLEMS IN $q$-UNIFORMLY SMOOTH BANACH SPACES
}

\author{
UAMPORN WITTHAYARAT*, CHAICHANA JAIBOON**, SOMYOT PLUBTIENG*** AND \\ PHAYAP KATCHANG**** \\ * Department of Mathematics, School of Science, University of Phayao \\ Phayao 56000, Thailand \\ E-mail: u.witthayarat@hotmail.com \\ ** Department of Mathematics, Faculty of Liberal Arts \\ Rajamangala University of Technology Rattanakosin \\ Nakhon Pathom 73170, Thailand \\ E-mail: chaichana.jai@rmutr.ac.th \\ ***Department of Mathematics, Faculty of Science, Naresuan University \\ Phitsanulok 65000, Thailand \\ E-mail: somyotp@nu.ac.th \\ ****Division of Mathematics, Faculty of Science and Agricultural Technology \\ Rajamangala University of Technology Lanna Tak, Tak 63000, Thailand \\ E-mail: p.katchang@rmutl.ac.th
}

\begin{abstract}
In this research, we focus on two main problems, the first one is a fixed point problem of a nonexpansive semigroup and the other is a variational inequality problem for an inverse strongly accretive mapping. Passing through the modified Mann iterative method, we propose the new iterative scheme to find the common elements solving our mentioned problems. Furthermore, we aim to obtain some strong convergence theorems under certain appropriate conditions in the $q$-uniformly smooth Banach spaces. Our results improve and extend resulting outcomes in the literature.

Key Words and Phrases: Banach space, fixed point, inverse-strongly accretive mapping, nonexpansive semigroup, $q$-uniformly smooth, variational inequality.

2010 Mathematics Subject Classification: 46B80, 47H06, 47H09, 47H10, 47H20, 47J20.

Acknowledgements. The authors would like to thank Prof.Somyot Plubtieng for the insightful comments and suggestions. We would like to thank Asst.Prof.Dr.Prasit Cholamjiak from University of Phayao, Thailand and Dr.Pongsakorn Sunthrayuth from Rajamangala University of Technology Thanyaburi, Thailand for the Example suggestion. This research was supported by the Commission on Higher Education, the Thailand Research Fund, and the Rajamangala University of Technology Lanna Tak (Grant no. TRG5880203).
\end{abstract}




\section{REFERENCES}

[1] A.S. Alofi, N. Hussain, W. Takahashi, Strong convergence theorems by hybrid method for semigroups of not necessarily continuous mappings in Banach spaces, Fixed Point Theory, 17(2016), 237-253.

[2] K. Aoyama, Y. Kimura, W. Takahashi, M. Toyoda, Approximation of common fixed point of a countable family of nonexpansive mapping in a Banach space, Nonlinear Anal. - Theory, Methods and Applications, 67(2007), 2350-2360.

[3] K. Aoyama, H. Liduka, W. Takahashi, Weak convergence of an iterative sequence for accretive operators in Banach spaces, Fixed Point Theory Appl., 2006, Article ID 35390, 13 pages.

[4] F.E. Browder, Nonlinear operators and nonlinear equations of evolution in Banach space, Proceedings of Symposia in Pure Mathematics, 18(1976), 78-81.

[5] S.S. Chang, H.W.J. Lee, C.K. Chan, Generalized system for relaxed cocoercive variational inequalities in Hilbert spaces, Applied Math. Letters, 20(2007), 329-334.

[6] Y.J. Cho, Y. Yao, H. Zhou, Strong convergence of an iterative algorithm for accretive operators in Banach spaces, J. Computational Anal. Appl., 10(2008), 113-125.

[7] I. Cioranescu, Geometry of Banach Spaces, Duality Mappings and Nonlinear Problems, Kluwer, Dordrecht, 1990.

[8] R. De Marr, Common fixed points for commuting contraction mappings, Pacific J. Math., 13(1963), 1139-1141.

[9] K. Goebel, S. Reich, Uniform Convexity, Hyperbolic Geometry, and Nonexpansive Mappings, Marcel Dekker, New York, 1984.

[10] J.P. Gossez, E.L. Dozo, Some geometric properties related to the fixed point theory for nonexpansive mappings, Pacific J. Math., 40(1972), 565-573.

[11] W.-B. Guan, An iterative method for variational inequality problems, J. Ineq. Appl., 2013, 2013:574, https://doi.org/10.1186/1029-242X-2013-574.

[12] Y.-X. Guo, M.-Z. Xue, Characterizations of common fixed points of one-parameter nonexpansive semigroups, Fixed Point Theory, 16(2015), 337-342.

[13] H. Ishihara, W. Takahashi, A nonlinear ergodic theorem for a reversible semigroup of Lipschitzian mappings in a Hilbert space, Proc. Amer. Math. Soc., 104(1988), 431-436.

[14] J.S. Jung, Convergence of viscosity iterative schemes for nonexpansive semigroups, Fixed Point Theory, 11(2010), 289-300.

[15] H.S. Kim, Th. Kim, Weak convergence of semigroups of asymptotically nonexpansive type on a Banach space, Comm. Korean Math. Soc., 2(1987), 63-69.

[16] S. Kitahara, W. Takahashi, Image recovery by convex combinations ot sunny nonexpansive retractions, Methods in Nonlinear Anal., 2(1993), 333-342.

[17] S. Kitahara, W. Takahashi, Strong convergence of a proximal-type algorithm in a Banach space, SIAM J. Optimization, 13(2002), 938-945.

[18] E. Kopecka, S. Reich, Nonexpansive retracts in Banach spaces, Banach Center Publications, 77(2007), 161-174.

[19] A.T.-M. Lau, Semigroup of nonexpansive mappings on a Hilbert space, J. Math. Anal. Appl., 105(1985), 514-522.

[20] A.T.-M. Lau, Amenability and fixed point property for semigroup of nonexpansive mapping, In: M.A. Thera, J.B. Baillon (eds.) Fixed Point Theory and Applications, in: Pitman Res. Notes Math. Ser, vol. 252, Longman Sci. Tech., Harlow, 1991, 303-313.

[21] A.T.-M. Lau, Invariant means and fixed point properties of semigroup of nonexpansive mappings, Taiwanese J. Math., 12(2008), 1525-1542.

[22] A.T.-M. Lau, H. Miyake, W. Takahashi, Approximation of fixed points for amenable semigroups of nonexpansive mappings in Banach spaces, Nonlinear Anal., 67(2007), 1211-1225.

[23] A.T.-M. Lau, H. Miyake, W. Takahashi, Fixed point properties for semigroup of nonexpansive mappings on Fréchet spaces, Nonlinear Anal., 70, 3837-3841.

[24] A.T.-M. Lau, N. Shioji, W. Takahashi, Existence of nonexpansive retractions for amenable semigroups of nonexpansive mappings and nonlinear ergodic theorems in Banach space, J. Functional Anal., 191(1999), 62-75. 
[25] A.T.-M. Lau, Y. Zhang, Fixed point properties od semigroups of nonexpansive mappings, J. Functional Anal., 245(2008), 2534-2554.

[26] T.C. Lim, Characterization of normal structure, Proc. Amer. Math. Soc., 43(1974), 313-319.

[27] T.C. Liu, Ishikawa and Mann iterative processes with errors for nonlinear strongly accretive mappings in Banach spaces, J. Math. Anal. Appl., 194(1995), 114-125.

[28] D.S. Mitrinovic, Analytic inequalities, Springer, New York, 1970.

[29] X. Qin, A.M. Kang, M. Shang, Generalized system for relaxed cocoercive variational inequalities in Hilbert spaces, Applicable Anal., 87(2008), 421-430.

[30] S. Reich, Constructive techniques for accretive and monotone operators, in "Applied Nonlinear Analysis", Academic Press, New York, 1979, 335-345.

[31] S. Reich, Review of Geometry of Banach spaces, Duality Mappings and Nonlinear Problems by Ioana Cioranescu, Kluwer Academic Publishers, Dordrecht, 1990, Bull. Amer. Math. Soc., 26(1992), 367-370.

[32] S. Reich, Asymptotic behavior of contractions in Banach spaces, J. Math. Anal. Appl., 44(1973), $57-70$.

[33] Y. Song, L. Ceng, A General iteration scheme for variational in equality problem and common fixed point problems of nonexpansive mapping in q-uniformly smooth Banach spaces, J. Global Optimization, $\mathbf{5 7}$ (2013), 1327-1348.

[34] P. Suntrayuth, P. Kumam, Iterative methods for variational inequality problems and fixed point problems of a countable family of strict pseudo-contractions in a q-uniformly smooth Banach space, Fixed Point Theory Appl., 2012, 2012:65, https://doi.org/10.1186/1687-1812-2012-65.

[35] T. Suzuki, Strong convergence of Krasnoselskii and Mann's type sequences for one-parameter nonexpansive semigroups without Bochner integrals, J. Math. Anal. Appl., 305(2005), 227-239.

[36] W. Takahashi, Fixed point theorem for amenable semigroups of nonexpansive mappings, Kodai Math. Seminar Reports, 21(1969), 383-386.

[37] W. Takahashi, A nonlinear ergodic theorem for a reversible semigroup of nonexpansive mappings in a Hilbert space, Proc. Amer. Math. Soc., 97(1986), 55-58.

[38] Y. Wang, H.K. Xu, Hybrid method for a class of accretive variational inequalities involving nonexpansive mappings, J. Ineq. Appl., 2014, 2014:217, https://doi.org/10.1186/1029-242X2014-217.

[39] R. Wangkeeree, P. Preechasilp, Modified Noor iterations for nonexpansive semigroups with generalized contraction in Banach spaces, J. Ineq. Appl., 2012 2012:6, https://doi.org/10.1186/1029-242X-2012-6.

[40] H.K. Xu, Inequalities in Banach spaces with applications, Nonlinear Anal., 16(1991), 1127-1138.

[41] H.K. Xu, Viscosity approximation methods for nonexpansive mappings, J. Math. Anal. Appl., 298(2004), 279-291.

Received: August 10, 2016; Accepted: May 18, $201 \%$. 
